Cite this: RSC Adv., 2017, 7, 34694
Check for updates

\section{A visible-light-induced photoelectrochemical water-splitting system featuring an organo- photocathode along with a tungsten oxide photoanode $\uparrow$}

\author{
Yuto Kawai, ${ }^{a}$ Keiji Nagai ${ }^{b}$ and Toshiyuki Abe (D)*a
}

A photoelectrochemical water-splitting system featuring an organo-photocathode of a $\mathrm{p}-\mathrm{n}$ bilayer was studied, where $\mathrm{WO}_{3}$ was simultaneously utilized as a photoanode. Stoichiometric formation of $\mathrm{H}_{2}$ and $\mathrm{O}_{2}$ was found to occur due to the decomposition of water. In the reference system of a $\mathrm{WO}_{3}$ photoanode and Pt counter electrode, bias voltages more than $0.4 \mathrm{~V}$ were needed to be applied for water splitting; however, the present system successfully led to water decomposition by applying only a low voltage of $0.1 \mathrm{~V}$ to the system. In the present water-splitting system, oxidizing and reducing powers can be separately generated at the $\mathrm{WO}_{3}$ photoanode and organo-photocathode, respectively, which is distinct from the reference system. Furthermore, electron transfer from $\mathrm{WO}_{3}$ (conduction band) to the hole-retained $p$-type layer (valence band) in the organo-photocathode can efficiently occur for completing the photoelectrochemical process, thus, resulting in a high concentration of holes available for rate-limiting $\mathrm{O}_{2}$ evolution at $\mathrm{WO}_{3}$ on the basis of efficient charge separation.

Received 10th May 2017
Accepted 4th July 2017

DOI: $10.1039 / c 7 r a 05272 c$

rsc.li/rsc-advances

$\mathrm{H}^{+}{ }^{18-21}$ With respect to the position of valence band edge corresponding to oxidizing power, $\mathrm{WO}_{3}$ is similar to $\mathrm{TiO}_{2}{ }^{20-23}$ Therefore, making an effective use of the oxidizing power of $\mathrm{WO}_{3}$ can help in developing a visible-light-induced watersplitting system. For instance, when employing a system featuring an organo-photocathode for photoelectrochemical water splitting ( $c f$. Scheme 1), $\mathrm{TiO}_{2}$ photoanode was utilized in the overall splitting of water, particularly under bias-free condition. ${ }^{4}$ As reported by Honda and Fujishima, ${ }^{24}$ the watersplitting system, comprising $\mathrm{TiO}_{2}$ photoanode and Pt counter, is a typical instance, but it required chemical or electric bias for completing the water splitting process. ${ }^{25-29}$ evolution. ${ }^{\mathbf{1 0 - 1 7}} \mathrm{WO}_{3}$ cannot solely lead to the overall decomposition of water because the reducing power generated at its conduction band edge is insufficient for the evolution of $\mathrm{H}_{2}$ from $\mathrm{H}^{+} \cdot{ }^{18-21}$ In other words, some of the metal oxides (such as $\mathrm{WO}_{3}, \mathrm{Fe}_{2} \mathrm{O}_{3}$, etc.) can respond to visible-light energy; however, their conduction band edge of the d-orbital is forced on a downward shift, making it impossible for the reduction of

\footnotetext{
${ }^{a}$ Department of Frontier Materials Chemistry, Graduate School of Science and Technology, Hirosaki University, 3 Bunkyo-cho, Hirosaki 036-8561, Japan. E-mail: tabe@hirosaki-u.ac.jp

${ }^{b}$ Laboratory for Chemistry and Life Science, Institute of Innovative Research, Tokyo Institute of Technology, Suzukake-dai, Midori-ku, Yokohama 226-8503, Japan

$\dagger$ Electronic supplementary information (ESI) available: Experimental details, cyclic voltammograms at photoelectrodes, action spectrum for photocurrents generated at $\mathrm{WO}_{3}$, and its absorption spectrum and SEM images, and data of photoelectrochemical water splitting in the reference $\mathrm{WO}_{3}-\mathrm{Pt}$ system. See DOI: $10.1039 / \mathrm{c} 7 \mathrm{ra05272c}$
}

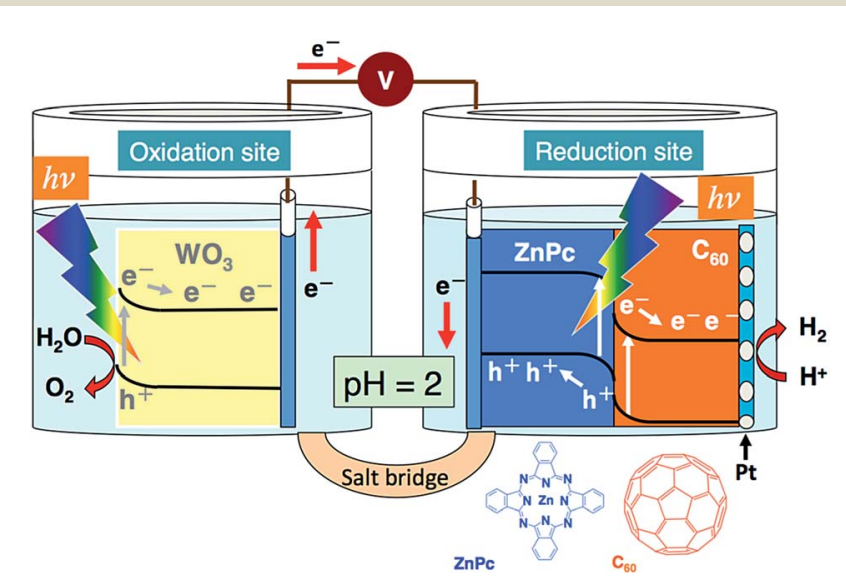

Scheme 1 An illustration of the system employed for water splitting. 
Photoelectrochemical and photocatalytic systems based on the utilization of both organic semiconductors and $\mathrm{p}-\mathrm{n}$ bilayer have been studied by our group. ${ }^{30-40}$ For example, an organic $\mathrm{p}-$ $\mathrm{n}$ bilayer of phthalocyanine [MPc ( $\mathrm{M}=\mathrm{H}_{2}$ or Zn), p-type] and fullerene $\left(\mathrm{C}_{60}, \mathrm{n}\right.$-type $)$ can function as a photocathode, where a reducing power can be generated at the $\mathrm{C}_{60}$ /water interface through a series of photophysical events within the bilayer. ${ }^{38-40}$ Particularly, in terms of molecular hydrogen evolution, when loading $\mathrm{Pt}$ on the $\mathrm{C}_{60}$ surface in the $\mathrm{MPc} / \mathrm{C}_{60}$ organophotocathode, it induced the reduction of $\mathrm{H}^{+}$at applied potentials that are more positive than the formal potential of $\mathrm{H}^{+} / \mathrm{H}_{2} \cdot{ }^{39,40}$

In the present study, a photoelectrochemical water-splitting system was investigated, where $\mathrm{WO}_{3}$ (photoanode) and Ptloaded $\mathrm{ZnPc}_{60}$ bilayer (photocathode, vide supra) were simultaneously employed in the system depicted in Scheme 1. The stoichiometric decomposition of water into $\mathrm{H}_{2}$ and $\mathrm{O}_{2}$ occurred on applying a bias voltage less than the theoretical voltage of $1.23 \mathrm{~V}$. It is noted that the present system successfully led to water decomposition under a low bias condition (i.e. 0.1 $\mathrm{V}$ ), where a reference system of $\mathrm{WO}_{3}$ photoanode and Pt counter cannot induce the redox reaction of water. Details of the results are discussed in the following sections.

\section{Experimental}

The $\mathrm{ZnPc} / \mathrm{C}_{60}$ bilayer was prepared by vapor deposition (pressure, $<1.0 \times 10^{-3} \mathrm{~Pa}$; deposition speed, ca. $0.03 \mathrm{~nm} \mathrm{~s}^{-1}$ ) using an indium-tin-oxide (ITO)-coated glass plate as the base material. ${ }^{40} \mathrm{ZnPc}$ was first coated on ITO, followed by the coating of $\mathrm{C}_{60}$ on top of the $\mathrm{ZnPc}$ layer; moreover, a Pt co-catalyst was photocathodically deposited onto the $\mathrm{C}_{60}$ surface of the bilayer. ${ }^{39,40}$ The resulting photocathode is abbreviated as ITO/

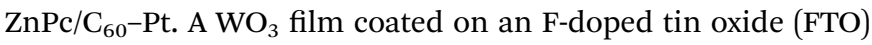
was prepared according to the following procedures. $\mathrm{WO}_{3}(72 \mathrm{~g}$, Kojundo Chemical Laboratory) and acetylacetone $(0.8 \mathrm{~mL}$, Wako Chemical) were mixed well in a mortar, and then, pure water $(24 \mathrm{~mL})$ was slowly added during $2 \mathrm{~h}$. Subsequently, Triton X-100 detergent ( $1 \mathrm{~mL}$, Aldrich) was added and mixed well with the resulting slurry of $\mathrm{WO}_{3}$, following which the mixture was subject to ultrasonic irradiation. Furthermore, the sample was centrifuged to eliminate large-sized particles of $\mathrm{WO}_{3}(1000 \mathrm{rpm}, 5 \mathrm{~min})$. This centrifugation process was repeated 3 times. The resulting suspension of $\mathrm{WO}_{3}(800 \mu \mathrm{L})$ was spin-coated (2000 rpm, $1 \mathrm{~min})$ on an FTO electrode $(4 \times 4 \mathrm{~cm})$, followed by drying at $373 \mathrm{~K}$ for $30 \mathrm{~min}$. The processes of both spin-coating and drying were repeated 3 times. Prior to use, the resulting film was calcined in an electric furnace [at $823 \mathrm{~K}$ for $2 \mathrm{~h}$ (rate of temperature rising: $2{ }^{\circ} \mathrm{C} \mathrm{min}^{-1}$ )]. The SEM image of the $\mathrm{WO}_{3}$ film is shown in Fig. $\mathrm{S} 1$ (in the ESI $\dagger$ ). The photoanode of $\mathrm{WO}_{3}$ is denoted as $\mathrm{FTO} / \mathrm{WO}_{3}$. FTO is usually utilized in preparing photoelectrodes at a high temperature, in order to avoid an unfavorable increase of sheet resistance. ${ }^{41}$ The preparation of $\mathrm{FTO} / \mathrm{WO}_{3}$ was conducted by modifying a method for FTO/TiO ${ }_{2}{ }^{41}$ The aforementioned conditions of $\mathrm{FTO} / \mathrm{WO}_{3}$ preparation were optimal ( $c f$. thickness of $\left.\mathrm{WO}_{3}, c a .1 \mu \mathrm{m}\right)$. The effective area of all the photoelectrodes employed was $1 \mathrm{~cm} \times$
$1 \mathrm{~cm}$. A cell made up of twin compartments separated by a salt bridge was utilized for the water-splitting studies (see Scheme 1). All studies were performed under an Ar atmosphere in an aqueous $\mathrm{H}_{3} \mathrm{PO}_{4}$ solution $(\mathrm{pH}=2)$. Other experimental details are provided in the ESI. $\dagger$

\section{Results and discussion}

Cyclic voltammogram (CV) was measured at $\mathrm{FTO} / \mathrm{WO}_{3}$ photoanode in an $\mathrm{H}_{3} \mathrm{PO}_{4}$ solution (Fig. S2 in the ESI $\dagger$ ), where a threeelectrode system was employed for the voltammetric measurement (see Scheme S1 in the ESI $\dagger$ ). CV measured at ITO/ZnPc/ $\mathrm{C}_{60}-\mathrm{Pt}$ photocathode is also depicted in Fig. S2. $\dagger^{40}$ Considering the formal potentials for $\mathrm{H}^{+}$reduction $(-0.32 \mathrm{~V} v s$. $\mathrm{Ag} / \mathrm{AgCl}$ (sat.) for $\mathrm{H}^{+} / \mathrm{H}_{2}$ couple) and water oxidation $(+0.91 \mathrm{~V} v s$. $\mathrm{Ag} / \mathrm{AgCl}$ (sat.) for $\mathrm{O}_{2} / \mathrm{H}_{2} \mathrm{O}$ couple) at $\mathrm{pH}=2$, the voltammograms indicated that the photo-induced reactions for $\mathrm{H}_{2}$ evolution and $\mathrm{O}_{2}$ evolution can efficiently occur at both photoelectrodes. In other words, a photoelectrochemical water splitting can be expected to take place under the condition of a low bias voltage, on the basis of the evidence that both photoanodic and photocathodic currents occurred at close potentials.

In addition, action spectrum for the photocurrents generated at $\mathrm{FTO} / \mathrm{WO}_{3}$ photoanode was measured, where the same setup as the voltammetric measurement was employed ( $c f$. Scheme $\mathrm{S} 1 \dagger)$. The resulting action spectrum acquired at the photoanode of $\mathrm{WO}_{3}$ was consistent with its absorption spectrum (Fig. S1 $\dagger$ ), indicating that a photocurrent can be generated due to the bandgap excitation of $\mathrm{WO}_{3}$ [ $c f$. the magnitude of its band-gap was in accordance with the reported value ( $c a .2 .7 \mathrm{eV}$ ) corresponding to the absorption edge of $\left.c a .460 \mathrm{~nm}^{18,21,23,42,43}\right]$. As for the ITO/ZnPc/ $\mathrm{C}_{60}-\mathrm{Pt}$ photocathode capable of $\mathrm{H}_{2}$ evolution, its action spectrum has previously been clarified to originate in the entire visible-light absorption of both $\mathrm{ZnPc}$ and $\mathrm{C}_{60} \cdot{ }^{40}$

According to Scheme 1, a photoelectrochemical water splitting was studied by applying bias voltages to the system. As a result, $\mathrm{H}_{2}$ evolution was found to occur along with $\mathrm{O}_{2}$ evolution, particularly at bias voltages less than $1.23 \mathrm{~V}$ (the theoretical voltage for water splitting). In other words, the stoichiometric decomposition of water took place in the present system. Fig. 1 shows the relationships between the amounts of $\mathrm{H}_{2}$ and $\mathrm{O}_{2}$ evolved and the applied voltages. Note that the application of only a low bias voltage of $0.1 \mathrm{~V}$ to the system led to water splitting, although voltages more than $0.3 \mathrm{~V}$ are usually needed to be applied to the reference system of $\mathrm{WO}_{3}$ photoanode and $\mathrm{Pt}$ counter (vide infra). ${ }^{11,15-17,21,44,45}$ The $\mathrm{H}_{2}$ and $\mathrm{O}_{2}$ amounts essentially increased with elevating applied voltages; however, the evolved amounts became gentle at voltages larger than 0.6 V. Based on the data of water splitting, the light-tohydrogen conversion efficiency $(\eta$, see the ESI $\uparrow$ concerning the calculation method) was estimated with respect to the applied voltages (Fig. 1). The most efficient water splitting occurred at $0.6 \mathrm{~V}$ with $c a$. $0.07 \%$ while the $\eta$ value decreased with higher voltages. Applied bias voltages can lead to efficient charge separation along with an efficient charge transfer between both photoelectrodes, where the amounts of $\mathrm{H}_{2}$ and $\mathrm{O}_{2}$ may increase to involve the increasing concentration of carriers available for 


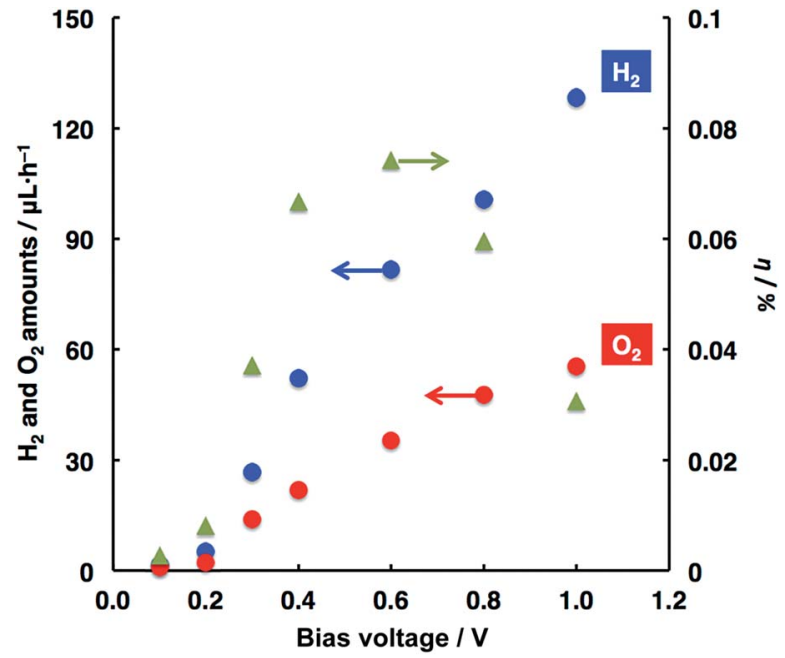

Fig. 1 Relationships of the evolved $\mathrm{H}_{2}$ and $\mathrm{O}_{2}$ amounts and $\eta$ values with applied voltages. This study was conducted in the two-electrode system depicted in Scheme 1. Faradaic efficiencies for $\mathrm{H}_{2}$ and $\mathrm{O}_{2}$ evolution were typically $>90 \%$ and $>80 \%$, respectively (see ESI $\dagger$ ). Photoanode, $\mathrm{WO}_{3}$ (geometrical area, $1 \mathrm{~cm}^{2}$ ); photocathode, ITO/ZnPC $(75 \mathrm{~nm}) / \mathrm{C}_{60}(125 \mathrm{~nm})-\mathrm{Pt}$ (geometrical area, $\left.1 \mathrm{~cm}^{2}\right)$; electrolyte, $\mathrm{H}_{3} \mathrm{PO}_{4}$ solution ( $\mathrm{pH}=2$ ); light intensity (for photoanode), ca. $50 \mathrm{~mW} \mathrm{~cm}^{-2}$; light intensity (for photocathode), ca. $90 \mathrm{~mW} \mathrm{~cm}^{-2}$.

water decomposition. A decreasing value of $\eta$ is attributed to a non-linear increase of carrier concentration with applied voltages, thus resulting in a moderate enhancement of kinetics for $\mathrm{H}_{2}$ and $\mathrm{O}_{2}$ formation. Such a phenomenon was also represented in another system of photoelectrochemical water splitting.,44-49

A prolonged study of water splitting was conducted to examine the durability of the present system, where both photoanode and photocathode were repeatedly used with the cycle number. As shown in Fig. 2, the amounts of $\mathrm{H}_{2}$ and $\mathrm{O}_{2}$ evolved linearly increased with the cycle number, demonstrating stable and durable performance for water splitting.

Control experiments were conducted in the presence of methanol (electron donor) or $\mathrm{Fe}^{3+}$ ion (electron acceptor), which are compared with a typical result of photoelectrochemical water splitting (Table 1). Irrespective of the presence of $\mathrm{Fe}^{3+}$ ion, the amount of $\mathrm{O}_{2}$ evolved was almost constant (Entries 1 and 2). The evolved amount of $\mathrm{H}_{2}$ noticeably increased in the presence of methanol (Entry 3). Therefore, these results suggest that the present system (i.e. Entry 1) is kinetically dominated by the evolution of $\mathrm{O}_{2}$ from water.

A reference system of $\mathrm{WO}_{3}$ photoanode and Pt counter (denoted as $\mathrm{WO}_{3}-\mathrm{Pt}$ system) was examined for photoelectrochemical water splitting. The results are summarized in Fig. S3. $\uparrow$ The $\mathrm{WO}_{3}-\mathrm{Pt}$ system resulted in the evolution of both $\mathrm{H}_{2}$ and $\mathrm{O}_{2}$ only when high voltages $($ i.e. $\geq 0.4 \mathrm{~V}$ ) were applied to the system. This is reasonable since the bottom edge of the conduction band of $\mathrm{WO}_{3}$, corresponding to the position of reducing power, is $0.3 \mathrm{~V}$ positive for the formal potential of $\mathrm{H}^{+} / \mathrm{H}_{2}$ (vide supra). ${ }^{18-21}$ Fig. S3† showed similar dependencies of both the evolved amounts and $\eta$ values on bias voltages to Fig. 1. In a separate experiment, the rate-limiting reaction in the $\mathrm{WO}_{3}-\mathrm{Pt}$

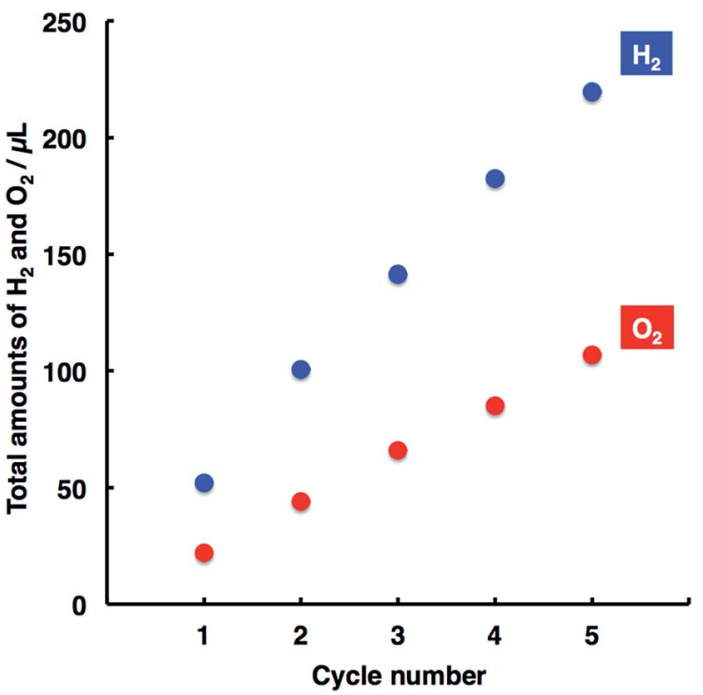

Fig. 2 Relationships between the $\mathrm{H}_{2}$ and $\mathrm{O}_{2}$ amounts with cycle number. Experimental conditions were the same as those used in Fig. 1. The bias voltage of $0.4 \mathrm{~V}$ was applied to the system, and the irradiation time was $1 \mathrm{~h}$ per one cycle.

system was investigated in the presence of methanol or $\mathrm{Fe}^{3+}$ ion. As shown in Table S1 (in the ESI $\dagger$ ), it was confirmed that the ratelimiting $\mathrm{O}_{2}$ evolution occurs in the reference system.

As for $\mathrm{WO}_{3}$ photoanode ${ }^{10-17}$ and $\mathrm{ITO} / \mathrm{ZnPc} / \mathrm{C}_{60}-\mathrm{Pt}$ photocathode, ${ }^{40}$ those photoelectrochemical reactivities for water reaction have previously been elucidated. The most typical characteristics of the present system are that oxidizing and reducing powers are separately generated at $\mathrm{WO}_{3}$ and ITO/ZnPc/ $\mathrm{C}_{60}-\mathrm{Pt}$, respectively. Furthermore, as indicated in Scheme 1, the excited electron generated at $\mathrm{WO}_{3}$ can be transferred to the hole-remained valence band of $\mathrm{ZnPc}$ for accomplishing photoelectrochemical water splitting, through which the pristine species of $\mathrm{WO}_{3}$ and $\mathrm{ZnPc}$ can be regenerated. This is distinct from the reference $\mathrm{WO}_{3}-\mathrm{Pt}$ system where the reducing power photogenerated at $\mathrm{WO}_{3}$ can directly participate in the evolution of $\mathrm{H}_{2}$ from $\mathrm{H}^{+}$. In Table 2, the typical comparison of the $\mathrm{WO}_{3}-\mathrm{Pt}$ system with the $\mathrm{WO}_{3}$ and $\mathrm{ITO} / \mathrm{ZnPc} / \mathrm{C}_{60}-\mathrm{Pt}$ system is shown. As aforementioned, those systems involve the rate-limiting $\mathrm{O}_{2}$ evolution. The amounts of $\mathrm{H}_{2}$ and $\mathrm{O}_{2}$ originating from water

Table 1 Control experiment data with the $\mathrm{WO}_{3}$ (photoanode) and ITO/ZnPc/ $\mathrm{C}_{60}-\mathrm{Pt}$ (photocathode) system ${ }^{a}$

\begin{tabular}{llll}
\hline System & $\begin{array}{l}\mathrm{H}_{2} \text { amount } \\
\left(\mu \mathrm{L} \mathrm{h} h^{-1}\right)\end{array}$ & $\begin{array}{l}\mathrm{O}_{2} \text { amount } \\
\left(\mu \mathrm{L} \mathrm{h}^{-1}\right)\end{array}$ & Note \\
\hline${\text { Entry } 1^{b}}_{\text {Entry }^{c}}^{c}$ & 81.8 & 35.4 & $\begin{array}{l}\text { No control system } \\
\text { In the presence of } \\
\text { methanol }\end{array}$ \\
Entry $3^{d}$ & 150 & - & $\begin{array}{l}\text { In the presence of } \mathrm{Fe}^{3+} \\
\text { In }\end{array}$
\end{tabular}

${ }^{a}$ Bias voltage of $0.6 \mathrm{~V}$ was applied for the system with experimental conditions similar to those in Fig. $1 .{ }^{b}$ Data from Fig. $1 .{ }^{c}$ A methanol solution (methanol/water(v/v) $=1: 1, \mathrm{pH}=2$ ) was used. ${ }^{d}$ An aqueous solution of $\mathrm{Fe}\left(\mathrm{NO}_{3}\right)_{3}(5 \mathrm{mM}, \mathrm{pH}=2)$ was employed. 
Table 2 Comparison of water splitting data in the present system to the $\mathrm{WO}_{3}-\mathrm{Pt}$ system ${ }^{a}$

\begin{tabular}{lllll}
\hline System & Photoanode & Cathode & $\begin{array}{l}\mathrm{H}_{2} \text { amount } \\
\left.(\mu \mathrm{L} \mathrm{h})^{-1}\right)\end{array}$ & $\begin{array}{l}\mathrm{O}_{2} \text { amount } \\
\left(\mu \mathrm{L} \mathrm{h}^{-1}\right)\end{array}$ \\
\hline${\text { Entry } 1^{b}}^{c}$ & $\mathrm{WO}_{3}$ & ITO/ZnPc/C & \\
Entry $^{c}$ & $\mathrm{WO}_{3}$ & Pt wire & 81.8 & 35.4 \\
& & 13.5 & 7.82
\end{tabular}

${ }^{a}$ Bias voltage of $0.6 \mathrm{~V}$ was applied to the system, and other experimental conditions were similar to those of Fig. $1 .{ }^{b}$ Data from Fig. $1{ }^{c}$ Instead of $\mathrm{ITO} / \mathrm{ZnPc} / \mathrm{C}_{60}-\mathrm{Pt}$, a Pt wire was employed as a cathode; data listed in this table can also be seen in Fig. S3.†

splitting were greater in the latter system. The difference between those systems is attributable to the magnitude of charge separation. In other words, the steady concentration of holes available for $\mathrm{O}_{2}$ evolution can be considered to be higher in the $\mathrm{WO}_{3}$ and ITO/ZnPc/C 60 -Pt system. This may indicate that the electron transport between the photoelectrodes employed (vide supra) efficiently occurs for producing the higher concentration of carriers.

\section{Conclusions}

This work studied the photoelectrochemical water-splitting system featuring an organo-photocathode along with a $\mathrm{WO}_{3}$ photoanode, where the stoichiometric decomposition of water into $\mathrm{H}_{2}$ and $\mathrm{O}_{2}$ was found to occur. Based on the action spectral characteristics of both ITO/ZnPc/ $\mathrm{C}_{60}-\mathrm{Pt}$ photocathode and $\mathrm{WO}_{3}$ photoanode, a visible-light energy was available for water splitting. In the reference $\mathrm{WO}_{3}-\mathrm{Pt}$ system, the bias voltages more than $0.4 \mathrm{~V}$ needed to be applied for evolving $\mathrm{H}_{2}$ and $\mathrm{O}_{2}$; however, the present system demonstrated that extremely lowbiased water splitting can occur. Distinct from the reference system, oxidizing and reducing powers for water splitting were separately generated at $\mathrm{WO}_{3}$ photoanode and $\mathrm{ITO} / \mathrm{ZnPc} / \mathrm{C}_{60}-\mathrm{Pt}$ photocathode, respectively. Irrespective of the systems studied, the evolution of $\mathrm{O}_{2}$ from water was the rate-limiting step. However, in the present system, the electron transfer from $\mathrm{WO}_{3}$ (CB) to hole-remained $\mathrm{ZnPc}(\mathrm{VB})$ can efficiently occur for producing a high concentration of carriers available for $\mathrm{O}_{2}$ evolution. The application of two types of materials for water splitting is an effective method, which can be seen in the Zscheme type photocatalytic water-splitting system ${ }^{\mathbf{5 0 - 5 2}}$ as well as the present system. In these systems, the materials, which cannot solely participate in the overall decomposition of water, can play active parts. The utilization of distinct types of materials may also have merits in terms of harvesting of solar energy. Photoelectrochemical water decomposition is one of the most promising approaches for acquiring solar hydrogen. In this context, developing efficient photoelectrodes is a vital issue for establishing a practical water-splitting system.

\section{Acknowledgements}

This work was partly supported by a grant from The Murata Science Foundation (T. A.), Yashima Environment Technology
Foundation (T. A.), and the Cooperative Research Program of "Network Joint Research Center for Materials and Devices" (T. A.).

\section{References}

1 J. Su, L. Zhu and G. Chen, Appl. Catal., B, 2016, 186, 127-135.

2 M. Kodera, H. Urabe, M. Katayama, T. Hisatomi, T. Minegishi and K. Domen, J. Mater. Chem. A, 2016, 4, 7658-7664.

3 S. Ida, K. Yamada, M. Matsuka, H. Hagiwara and T. Ishihara, Electrochim. Acta, 2012, 82, 397-401.

4 T. Abe, K. Fukui, Y. Kawai, K. Nagai and H. Kato, Chem. Commun., 2016, 52, 7735-7737.

5 K. Tsuji, O. Tomita, M. Higashi and R. Abe, ChemSusChem, 2016, 9, 2201-2208.

6 T. Grewe and H. Tüysüz, J. Mater. Chem. A, 2016, 4, 30073017.

7 J. Yan, H. Wu, H. Chen, Y. Zhang, F. Zhang and S. Liu, Appl. Catal., B, 2016, 190, 130-137.

8 R. Kobayashi, T. Takashima, S. Tanigawa, S. Takeuchi, B. Ohtani and H. Irie, Phys. Chem. Chem. Phys., 2016, 18, 27754-27760.

9 Q. Wang, T. Hisatomi, Q. Jia, H. Tokudome, M. Zhong, C. Wang, Z. Pan, T. Takata, M. Nakabayashi, N. Shibata, Y. Li, I. Sharp, A. Kudo, T. Yamada and K. Domen, Nat. Mater., 2016, 15, 611-615.

10 J. Zhang, H. Ma and Z. Liu, Appl. Catal., B, 2017, 201, 84-91. 11 C. Fàbrega, S. Murcia-López, D. Monllor-Satoca, J. D. Prades, M. D. Hernández-Alonso, G. Penelas, J. R. Morante and T. Andreu, Appl. Catal., B, 2016, 189, 133-140.

12 X. Shi, I. Herraiz-Cardona, L. Bertoluzzi and P. Lopez-Varo, Phys. Chem. Chem. Phys., 2016, 18, 9255-9261.

13 J. Zhao, E. Olide and F. E. Osterloh, J. Electrochem. Soc., 2015, 162, H65-H71.

14 D. Chandra, K. Saito, T. Yui and M. Yagi, Angew. Chem., Int. Ed., 2013, 52, 12606-12609.

15 A. Kleiman-Shwarsctein, A. B. Laursen, F. Cavalca, W. Tang, S. Dahla and I. Chorkendorff, Chem. Commun., 2012, 48, 967-969.

16 R. Liu, Y. Lin, L.-Y. Chou, S. W. Sheehan, W. He, F. Zhang, H. J. M. Hou and D. Wang, Angew. Chem., Int. Ed., 2011, 50, 499-502.

17 C. Santato, M. Ulmann and J. Augustynski, J. Phys. Chem. B, 2001, 105, 936-940.

18 B. D. Alexander, P. J. Kulesza, I. Rutkowska, R. Solarskac and J. Augustynski, J. Mater. Chem., 2008, 18, 2298-2303.

19 S. Sfaelou, L.-C. Pop, O. Monfort, V. Dracopoulos and P. Lianos, Int. J. Hydrogen Energy, 2016, 41, 5902-5907.

20 K. Maeda and K. Domen, J. Phys. Chem. C, 2007, 111, 78517861.

21 T. Jin, P. Diao, Q. Wu, D. Xu, D. Hu, Y. Xie and M. Zhang, Appl. Catal., B, 2014, 148-149, 304-310.

22 Q. Mi, A. Zhanaidarova, B. S. Brunschwig, H. B. Gray and N. S. Lewis, Energy Environ. Sci., 2012, 5, 5694-5700.

23 D. Monllor-Satoca, L. Borja, A. Rodes, R. Gómez and P. Salvador, ChemPhysChem, 2006, 12, 2540-2551. 
24 A. Fujishima and K. Honda, Nature, 1972, 238, 37-38.

25 L. N. Quan, Y. H. Jang, K. A. Stoerzinger, K. J. May, Y. J. Jang, S. T. Kochuveedu, Y. Shao-Horn and D. H. Kim, Phys. Chem. Chem. Phys., 2014, 16, 9023-9030.

26 H. Li, J. Chen, Z. Xia and J. Xing, J. Mater. Chem. A, 2015, 3, 699-705.

27 S. Hernández, D. Hidalgo, A. Sacco, A. Chiodoni, A. Lamberti, V. Cauda, E. Tresso and G. Saracco, Phys. Chem. Chem. Phys., 2015, 17, 7775-7786.

28 M. S. Wrighton, D. S. Ginley, P. T. Wolczanski, A. B. Ellis, D. L. Morse and A. Linz, Proc. Natl. Acad. Sci. U. S. A., 1975, 72, 1518-1522.

29 A. Fujishima, K. Kohayakawa and K. Honda, J. Electrochem. Soc., 1975, 122, 1487-1489.

30 T. Abe, K. Nagai, S. Kabutomori, M. Kaneko, A. Tajiri and T. Norimatsu, Angew. Chem., Int. Ed., 2006, 45, 2778-2781.

31 K. Nagai, T. Abe, Y. Kaneyasu, Y. Yasuda, I. Kimishima, T. Iyoda and H. Imaya, ChemSusChem, 2011, 4, 727-730.

32 K. Nagai, Y. Yasuda, T. Iyoda and T. Abe, ACS Sustainable Chem. Eng., 2013, 1, 1033-1039.

33 T. Abe, M. Okumura, Y. Kikuchi, T. Itoh and K. Nagai, J. Mater. Chem. A, 2017, 5, 7445-7450.

34 P. Arunachalam, S. Zhang, T. Abe, M. Komura, T. Iyoda and K. Nagai, Appl. Catal., B, 2016, 193, 240-247.

35 D. Mendori, T. Hiroya, M. Ueda, M. Sanyoushi, K. Nagai and T. Abe, Appl. Catal., B, 2017, 205, 514-518.

36 T. Abe, N. Taira, Y. Tanno, Y. Kikuchi and K. Nagai, Chem. Commun., 2014, 50, 1950-1952.

37 T. Abe, Y. Tanno, N. Taira and K. Nagai, RSC Adv., 2015, 5, 46325-46329.
38 T. Abe, K. Nagai, K. Sekimoto, A. Tajiri and T. Norimatsu, Electrochem. Commun., 2005, 7, 1129-1132.

39 T. Abe, S. Tobinai, N. Taira, J. Chiba, T. Itoh and K. Nagai, J. Phys. Chem. C, 2011, 115, 7701-7705.

40 T. Abe, Y. Hiyama, K. Fukui, K. Sahashi and K. Nagai, Int. J. Hydrogen Energy, 2015, 40, 9165-9170.

41 R. Saito, H. Ueno, J. Nemoto, Y. Fujii, A. Izuoka and M. Kaneko, Chem. Commun., 2009, 2009, 3231-3233.

42 F. Amano, E. Ishinaga and A. Yamakata, J. Phys. Chem. C, 2013, 117, 22584-22590.

43 T. Jin, P. Diao, D. Xu and Q. Wu, Electrochim. Acta, 2013, 114, 271-277.

44 W. Zhao, Z. Wang, X. Shen, J. Li, C. Xu and Z. Gan, Int. J. Hydrogen Energy, 2012, 37, 908-915.

45 Y. Hou, F. Zuo, A. P. Dagg, J. Liu and P. Feng, Adv. Mater., 2014, 26, 5043-5049.

46 I. Fujimoto, N. Wang, R. Saito, Y. Miseki, T. Gunji and K. Sayama, Int. J. Hydrogen Energy, 2014, 39, 2454-2461.

47 J. Akikusa and S. U. M. Khan, Int. J. Hydrogen Energy, 2002, 27, 863-870.

48 M. Radecka, M. Rekas, A. Trenczek-Zajac and K. Zakrzewska, J. Power Sources, 2008, 181, 46-55.

49 M. Moriya, T. Minegishi, H. Kumagai, M. Katayama, J. Kubota and K. Domen, J. Am. Chem. Soc., 2013, 135, 3733-3735.

50 R. Abe, M. Higashi and K. Domen, ChemSusChem, 2011, 4, 228-237.

51 K. Maeda, M. Higashi, D. Lu, R. Abe and K. Domen, J. Am. Chem. Soc., 2010, 132, 5858-5868.

52 H. Kato, Y. Sasaki, N. Shirakura and A. Kudo, J. Mater. Chem. A, 2013, 1, 12327-12333. 